\title{
EVALUASI PENERAPAN PERMENAKER NO. 5 TAHUN 2018 DI PT. XYZ PABRIK PENGOLAHAN PADI DAN JAGUNG CABANG SUMBAWA NUSA TENGGARA BARAT
}

\author{
Eko Sutrisno $^{1 *}$, Dr. Andi Tirta, M. Sc ${ }^{2}$, Haryandi, S.T,.M.Eng. ${ }^{3}$ \\ 1* Mahasiswa Program Studi pascasarjana Menajemen Inovasi Universitas Teknologi Sumbawa \\ ${ }^{2}$ Fakultas Teknik Universitas Teknologi Sumbawa \\ ${ }^{3}$ Fakultas Teknologi Pertanian Universitas Teknologi Sumbawa \\ *Corresponding Author email: tirta78@gmail.com, haryandi@uts.ac.id
}

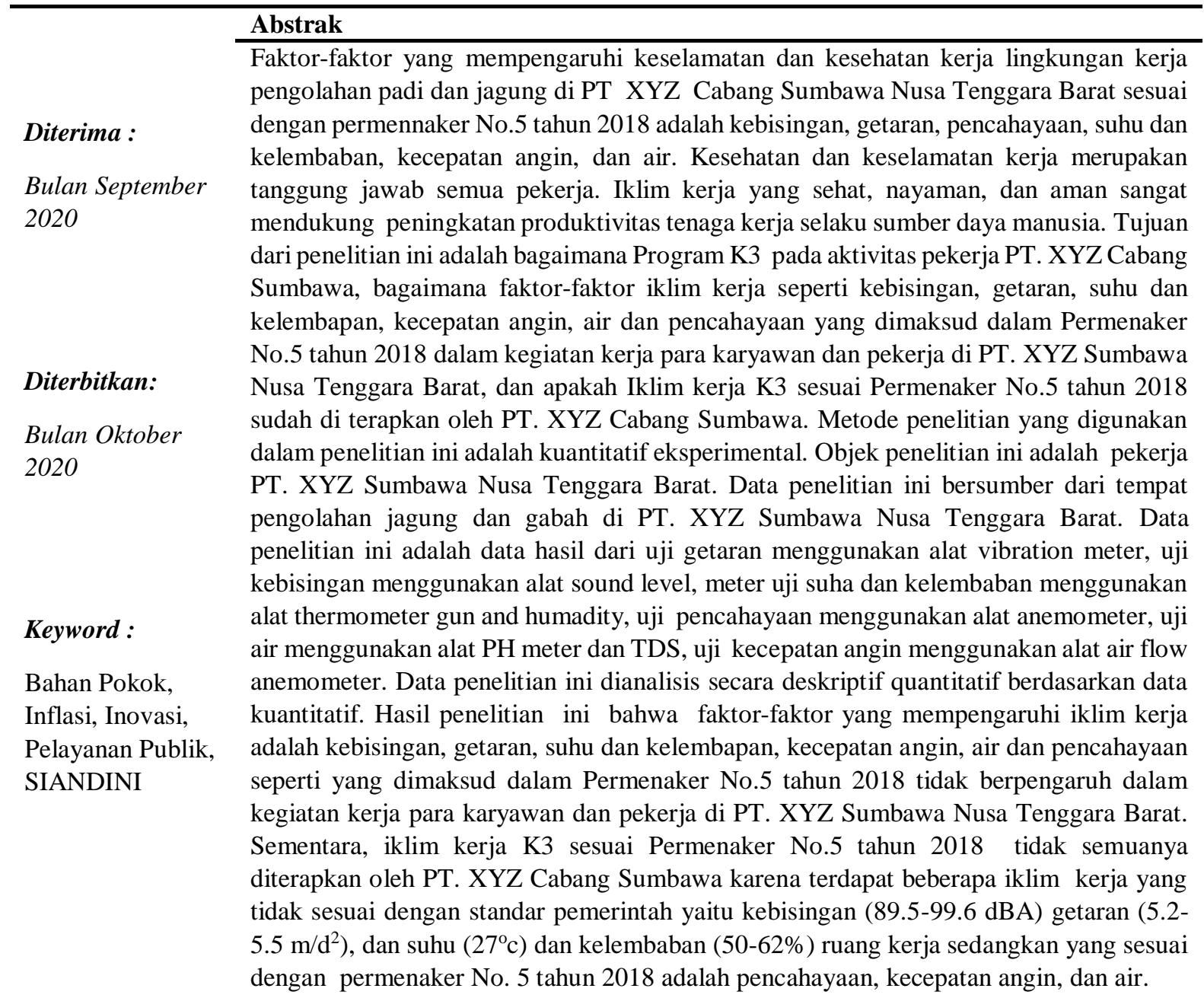

\section{A. PENDahuluan}

Keamanan, Keselamatan, dan Kesehatan Kerja (K3) merupakan suatu program yang dibuat untuk selalu di perhatikan, baik bagi perusahaan serta pekerjanya. Kesehatan dan keselamatan kerja adalah suatu kondisi dalam pekerjaan yang sehat dan aman baik itu bagi pekerjaannya, perusahaan maupun bagi masyarakat dan lingkungan sekitar pabrik atau tempat kerja tersebut ( Ridley, 1983).
Menurut Sedarmayanti (2011:124) ada 3 (tiga) tujuan dari sistem manajemen Kesehatan dan Keselamatan Kerja (K3) yaitu sebagai berikut:

1. Sebagai alat mencapai derajat kesehatan tenaga kerja yang setinggi-tingginya baik buruh, petani, nelayan, pegawai negeri, atau pekerja bebas.

2. Sebagai upaya mencegah dan memberantas penyakit dan kecelakaan akibat kerja, memelihara, dan meningkatkan kesehatan dan gizi tenaga 
kerja, merawat dan meningkatkan efisiensi dan daya produktivitas tenaga manusia, memberantas kelelahan kerja dan melipat gandakan gairah serta kenikmatan bekerja.

3. Memberi perlindungan bagi masyarakat sekitar perusahaan agar terhindar dari bahaya pengotoran bahan proses industrialisasi yang bersangkutan, dan perlindungan masyarakat luas dari bahaya yang mungkin ditimbulkan oleh produk industri.

Lingkungan tempat bekerja juga harus diperhatikan sesuai dengan Permenaker No.5 tahun 2018 tentang Keselamatan dan Kesehatan Kerja, dalam aturan Permenaker tersebut terdapat Faktor fisika yaitu Iklim Kerja yang berpengaruh dalam penerapan aturan K3. Iklim kerja tersebut meliputi kebisingan, getaran, gelombang radio/gelombang makro, radiasi ultra violet, medan magnet, tekanan udara, dan pencahayaan.

PT. XYZ merupakan salah satu perusahaan yang bergerak dibidang pertanian dan perkebunan di Kabupaten Sumbawa, yang mengolah hasil pertanian dan perkebuanan seperti padi dan jagung. Dalam kegiatan pengolahan tersebut, tentu saja banyak faktor resiko kecelakaan kerja yang harus di waspadai, terkait dengan iklim kerja yang telah dijelaskan diatas, faktor lingkungan kerja sangat berpengaruh dalam terjadinya kecelakaan kerja.

Untuk itu, perlu adanya penerapan K3 yang sesuia dengan Permenaker No.5 Tahun 2018. Tujuannya, untuk menjamin keselaman baik tenaga kerja maupun perusahaan. Akibatnya, semua kegiatan perusahaan akan sehat, aman, dan nyaman yang berlandaskan Permenaker No.5 Tahun 2018.

\section{B. RUMUSAN MASALAH}

Berdasarkan latar belakang yang telah dijelaskan di atas, maka rumusan masalah yang dikaji penulis dalam penelitian ini yaitu :

1. Bagaimana Program K3 pada aktivitas pekerja PT. XYZ Cabang Sumbawa?

2. Bagaimana faktor-faktor iklim kerja seperti kebisingan, getaran, suhu dan kelembapan, kecepatan angin, air dan pencahayaan yang dimaksud dalam Permenaker No.5 tahun 2018 di PT. XYZ Sumbawa Nusa Tenggara Barat?

3. Apakah Iklim kerja K3 sesuai Permenaker No.5 tahun 2018 sudah di terapkan oleh PT. XYZ Cabang Sumbawa?

\section{TUJUAN}

a. Untuk mengetahui program K3 pada aktivitas pekerja PT. XYZ Cabang Sumbawa.

b. Untuk mengetahui faktor-faktor iklim kerja seperti kebisingan, getaran, suhu dan kelembapan, kecepatan angin, air dan pencahayaan yang dimaksud dalam Permenaker No.5 tahun 2018 dalam kegiatan kerja para karyawan dan pekerja di PT. XYZ Sumbawa Nusa Tenggara Barat.

c. Untuk mengetahui Iklim kerja K3 sesuai Permenaker No.5 tahun 2018 yang terapkan oleh PT. XYZ Cabang Sumbawa.

\section{MANFAAT}

1. Dapat menjadi tambahan pengetahuan dan wawasan peneliti tentang budaya $\mathrm{K} 3$, memperaktekkan teori yang ada serta dapat memadukan kenyataan dan fakta yang terjadi dilapangan.

2. Sebagai referensi cabang ilmu yang sama tentang K3 dalam memecahkan masalah keilmuan $\mathrm{K} 3$ pada masa yang akan datang.

3. Membantu PT. di XYZ Sumbawa Nusa Tenggara Barat dalam mengevaluasi tentang penerapan budaya K3 terkait Keselamatan dan Kesehatan Kerja yang berpengaruh pada produksi hasil dari perusahaan tersebut.

\section{E. TINJAUAN PUSTAKA}

\section{Linkungan Kerja}

Lingkungan kerja adalah kombinasi dari suhu udara, kelembaban udara, kecepatan gerakan dan suhu radiasi (Suma'mur P.K, 1996: 84). Kombinasi keempat faktor tersebut bila dihubungkan dengan produksi panas oleh tubuh dapat disebut dengan tekanan panas.

Tekanan panas merupakan salah satu faktor fisik yang terdapat dilingkungan 
kerja, disebabkan oleh dua kemungkinan yaitu aliran udara dalam ruang kerja yang kurang baik atau sistem ventilasi yang kurang sempurna yaitu adanya sumber panas yang ada di lingkungan kerja seperti mesin uap, mesin diesel, mesin pengecor dan lain lain (Budiono, 2003) . maka dari itu, Indeks tekanan panas disuatu lingkungan kerja adalah perpaduan antara suhu udara, kelembaban udara, kecepatan gerakan udara, dan suhu radiasi yang menghasilkan panas metabolisme sebagai hasil aktivitas seseorang. Serangkaian urutan muatan lingkungan kerja tersebut menunjukkan bahwa lingkungan kerja adalah hasil perpaduan antara suhu, kelembaban udara, kecepatan gerakan angin dan panas radiasi dengan tingkat pengeluaran panas dari tubuh tenaga kerja sebagai akibat pekerjaannya.

Efisiensi kerja sangat dipengaruhi oleh suhu lingkungan kerja, bagi orang Indonesia daerah nikmat kerja sekitar $24^{\circ} \mathrm{c}-26^{\circ} \mathrm{c}$. Nilai Ambang Batas untuk cuaca (iklim) kerja adalah $21^{\circ} \mathrm{C}-30^{\circ} \mathrm{C}$ suhu basah (Suma'mur, P.K 1996). Oleh karena itu, lingkungan kerja yang tidak tepat dapat mengakibatkan gangguan kesehatan dan mengakibatkan kelelahan, yang pada akhirnya akan menurunkan produktifitas kerja.

\section{Pengendalian Lingkungan Kerja}

Lingkungan kerja yang aman dan nyaman serta sehat tidak selamanya selalu tercipta atau dapat dipertahankan. Maka dari itu, perlu adanya pengendalian lingkungan kerja agar lingkungan kerja tetap aman, nyaman, dan sehat. Alasannya, untuk menjaga produktivitas kerja sehingga memberikan hasil yang menguntungmemuaskan.

Pengendalian lingkungan kerja dapat dilakukan dengan cara administrative dan penggunaan alat pelindung diri (Ardyanto W, 2005).

\section{a. Pengendalian}

Secara

\section{Administratif}

Untuk menjaga sehat kerja, maka para pekerja dan pemberi kerja harus melakukan pemeriksaan kesehatan secara berkala, penyediaan dokter dan klinik kesehatan, pekerja terlibat dalam jamsostek, jam kerja selama $8 \mathrm{jam} / \mathrm{hari}$ atau $40 \mathrm{jam} / \mathrm{minggu}$ dengan waktu istirahat selama 1 jam/hari, dan adanya organisasi kesehatan keselamatan kerja.

b. Pengendalian Secara Penggunaan Alat Pelindung Diri

Pengadaan alat pelindung diri hendaknya dilakukan secara konsisten dan konsekuen agar tenaga kerja terhidar dari bahaya ditempat kerja seperti pemberian alat pelindung diri helm, masker penutup hidung dan mulut, sepatu dan pakaian kerja.

\section{Keamanan Keselamatan dan Kesehatan} Kerja

Keamanan, Keselamatan, dan Kesehatan Kerja (K3) merupakan suatu program yang dibuat untuk selalu di perhatikan, baik bagi perusahaan serta pekerjanya.

Kesehatan dan keselamatan kerja adalah suatu kondisi dalam pekerjaan yang sehat dan aman baik itu bagi pekerjaannya, perusahaan maupun bagi masyarakat dan lingkungan sekitar pabrik atau tempat kerja tersebut.

Sistem manajemen Kesehatan dan Keselamatan Kerja (K3) yaitu sebagai berikut:

a. Sebagai alat mencapai derajat kesehatan tenaga kerja yang setinggi-tingginya baik buruh, petani, nelayan, pegawai negeri, atau pekerja bebas.

b. Sebagai upaya mencegah dan memberantas penyakit dan kecelakaan akibat kerja, memelihara, dan meningkatkan kesehatan dan gizi tenaga kerja, merawat dan meningkatkan efisiensi dan daya produktivitas tenaga manusia, memberantas kelelahan kerja dan melipat gandakan gairah serta kenikmatan bekerja. 
c. Memberi perlindungan bagi masyarakat sekitar perusahaan agar terhindar dari bahaya pengotoran bahan proses industrialisasi yang bersangkutan, dan perlindungan masyarakat luas dari bahaya yang mungkin ditimbulkan oleh produk industri.

Hal tersebut menunjukkan bahwa Kesehatan dan keselamatan kerja merupakan upaya pemikiran serta penerapannya ditujukan untuk menjamin keutuhan dan kesempurnaan baik jasmaniah maupun rohaniah tenaga kerja khususnya dan manusia pada umumnya, hasil karya dan budaya, untuk meningkatkan kesejahteraan tenaga kerja. selain itu, kesehatan dan keselamatan kerja mengandung nilai perlindungan tenaga kerja dari kecelakaan atau penyakit akibat kerja. Tenaga kerja merupakan aset organisasi yang sangat berharga dan merupakan unsur penting dalam proses produksi disamping unsur lainnya seperti material, mesin dan lingkungan kerja (Mamahit, dkk, 2016).

Maka dari itu, untuk menunjang keefektifan kesehatan dan keselamatan kerja pada perusahaan, perlu majajemen massif oleh perusahaan agar produktivitas hasil dapat berkesinambungan baik pekerja maupun perusahaan itu sendiri. Alasannya, sistem manajemen K3 adalah bagian dari sistem manajemen perusahaan secara keseluruhan yang meliputi struktur organisasi, perencanaan, pelaksanaan, tanggung jawab, prosedur, proses dan sumber daya yang dibutuhkan bagi pengembangan, penerapan, pencapaian, pengkajian dan pemeliharaan kebijakan keselamatan dan kesehatan kerja dalam rangka pengendalian resiko yang berkaitan dengan kegiatan kerja guna terciptanya tempat kerja yang aman, efisien dan produktif.

\section{Iklim kerja}

Iklim kerja yang sehat, nayaman, dan aman sangat mendukung peningkatan produktivitas tenaga kerja selaku sumber daya manusia. Kondisi lingkungan kerja yang baik merupakan potensi untuk meraih produktivitas kerja yang baik pula. Alasanya, setiap pekerjaan selalu menuntut produktivitas kerja yang tinggi dan hanya dapat dicapai apabila kondisi iklim kerja yang tidak menimbulkan kecelakaan atau bahaya. Jadi, Untuk bekerja produktif, pekerjaan harus dilakukan dengan cara kerja pada lingkungan yang memenuhi syarat kesehatan (Suma'mur, 2009).

Tinggi rendahnya produktivitas tenaga kerja dipengaruhi oleh semangat dan faktor kenyamanan kerja dipengaruhi oleh faktor lingkungan kerja. Kemudian, ketidaknyamanan saat bekerja merupakan kondisi yang sangat tidak baik bagi tenaga kerja dalam beraktivitas karena pekerja akan melakukan aktivitasnya yang kurang optimal dan akan menyebabkan lingkungan kerja yang tidak bersemangat dan membosankan.

Singkatnya, iklim kerja sangat mempengaruhi proses dan hasil kerja oleh pekerja. Untuk itu, lingkungan fisik kerja di sekitar para pekerja haruslah diperhatikan agar mampu bekerja secara optimal.

\section{Faktor-Faktor Iklim Kerja}

Berdasarkan aturan pemerintah melalui permenaker No. 5 Tahun 2018 bahwa faktor-faktor yang mempengaruhi iklim kerja adalah kebisingan, getaran, penyacahaan, suhu dan kelembaban, kecepatan angin, dan air.

Semua faktor-faktor yang menggangu pekerjaan tersebut harus dapat di hindari atau distandarisasikan dengan permenaker No. 5 Tahun 2018.

\section{a. Kebisingan}

Menurut Keputusan Menteri Ketenagakerjaan No 05. tahun 2018, tentang Baku Mutu Tingkat Kebisingan, bahwa kebisingan adalah semua suara yang tidak dikehendaki yang bersumber dari alat-alat proses produksi dan/alatalat kerja yang pada tingkat tertentu dapat menimbulkan gangguan 
pendengaran. Tingkat kebisingan adalah ukuran energi bunyi yang dinyatakan dalam satuan desibel (dB), sedangkan baku mutu tingkat kebisingan adalah batas maksimal tingkat kebisingan yang diperbolehkan dibuang ke lingkungan dari suatu usaha atau kegiatan sehingga tidak menimbulkan gangguan kesehatan manusia dan kenyamanan lingkungan.

b. Getaran

Getaran adalah gerakan yang teratur dari benda atau media dengan arah bolak-balik dari kedudukan keseimbangannya (Keputusan Menteri Ketenagakerjaan Nomor 05 tahun 2018). Getaran terjadi saat mesin atau alat dijalankan dengan motor, sehingga pengaruhnya bersifat mekanis (Budiono, 2003). Getaran ialah gerakan ossilasi disekitar titik (Harrington, 1996). Vibrasia adalah gerakan dapat disebabkan oleh getaran udara atau getaran mekanis misalnya pada mesin atau alat-alat mekanis lainnya (Gabriel, 1996).

c. Pencahayaan

Kepmenkes No. 1405 Tahun 2002 bahwa pencahayaan adalah jumlah penyinaran pada suatu bidang kerja yang diperlukan untuk melaksanakan kegiatan secara efektif. Sementara itu, (Ahmadi, 2009) pencahayaan adalah adalah banyaknya cahaya yang tiba pada satu luas permukaan. Jadi, pencahayaan merupakan salah satu faktor untuk menciptakan lingkungan yang aman dan nyaman dan berkaitan erat dengan produktivitas manusia. Untuk mendapatkan pencahayaan yang sesuai dalam suatu ruang, maka diperlukan sistem pencahayaan yang tepat sesuai dengan kebutuhannya.

\section{d. Suhu dan kelembaban}

Keputusan Menteri Kesehatan RI nomor 1405/MENKES/SK/XI/2002 tentang Standard temperature bahwa area suhu pada area kerja industri berada pada kisaran 18-30 ${ }^{\circ} \mathrm{C}$. disamping itu, aturan ini mewajibkan perusahaan untuk mengambil langkah-langkah untuk menurunkan suhu di tempat kerja yang masih di atas 30 derajat, dan menggunakan metode yang direkomendasikan untuk melindungi buruh dari panas.

e. Kecepatan angin

Lingkungan kerja yang aman, nyaman, dan sejuk sangat mendorong atau merupakan pemicu semangat kerja. Maka dari itu, Tempat kerja yang nyaman merupakan salah satu faktor penunjang gairah kerja. Lingkungan kerja yang panas dan lembab akan menurunkan produktivitas kerja, juga akan membawa dampak negatif terhadap kesehatan dan keselamatan kerja (Fajrianti, dkk, 2017). Kecepatan angin merupakan bagian dari kajian K3 karena dapat menimbulkan bahaya atau kecelakaan kerja. Oleh karena itu, angin yang dianggap nikmat bagi orang Indonesia ialah berkisar $24^{\circ} \mathrm{c}-26^{\circ} \mathrm{c}$ dan selisih suhu didalam dan diluar tidak boleh lebih dari $5^{0} \mathrm{C}$. Batas kecepatan angin secara kasar yaitu 0,25 sampai $0,5 \mathrm{~m} / \mathrm{dtk}$.

f. Air

air bersih (Kodoatie, 2003) adalah air yang dipakai sehari-hari untuk keperluan mencuci, mandi, memasak dan dapat diminum setelah dimasak. Begitu pula dengan (Suripin, 2002) bahwa air bersih yaitu air yang aman (sehat) dan baik untuk diminum, tidak berwarna, tidak berbau, dengan rasa yang segar.

Apapun itu, mengingat akan pentingnya air bersih untuk kebutuhan manusia, maka kualitas 
air tersebut harus memenuhi persyaratan (Peraturan Menteri Kesehatan

No.416/PerMenKes/IX/1990) yaitu sebagai berikut:

1. Syarat fisik yaitu air harus bersih dan tidak keruh, tidak berwarna, tidak berbau dan tidak berasa, suhu antara $10 \mathrm{o}-$ 25 o C (sejuk).

2. Syarat kimiawi yaitu air tidak mengandung bahan kimiawi yang mengandung racun, tidak mengandung zat-zat kimiawi yang berlebihan, cukup yodium, $\mathrm{pH}$ air antara 6,5-9,2.

3. Syarat bakteriologi yaitu air tidak mengandung kumankuman penyakit seperti disentri, kolera dan bakteri patogen penyebab penyakit.

\section{F. METODE}

Penelitian ini merupakan sebuah penelitian kuantitatif eksperimental untuk mengidentifikasi atau menemukan dampak positif dan iklim kerja lingkungan K3 di PT. XYZ Cabang Sumbawa dan karyawannya sesuai dengan permenaker No. 5 Tahun 2018.

Tempat peneletian ini akan di PT. XYZ Cabang Sumbawa, Nusa Tenggara Barat yang berlokasi di jalan lintas SumbawaBima. Sample dalam penelitian ini yang diambil dari adalah sebagian dari iklim kerja lingkungan $\mathrm{K} 3$ yang sesuai dengan standar permenaker No. 5 Tahun 2018.

Alat yang digunakan untuk mengumpulkan data penelitian ini yaitu vibration meter untuk uji getaran, sound level meter untuk uji kebisingan, thermometer gun and humadity untuk uji suhu, anemometer untuk uji pencahayaan, PH meter dan TDS untuk uji air, dan air flow anemometer untuk uji kecepatan angin.

\section{G. HASIL DAN PEMBAHASAN}

\section{HASIL}

a. Pengaruh K3 pada aktifitas kerja di PT. XYZ Cabang Sumbawa

Setelah dilakukan penelitin langsung dilapangan yaitu di tempat pengolahan padi dan jagung di PT. XYZ Sumbawa Nusa Tenggara Barat bahwa PT tersebut menerapkan Permenaker No.5 tahun 2018 tentang keselamatan dan kesehatan kerja. Pada faktor lingkungan kerja pada tempat pengolahan padi dan jagung di di PT. XYZ Cabang Sumbawa Nusa Tenggara Barat menerapkan sistem lingkungan higienis. Hal ini berarti bahwa faktor fisika, kimia, biologi, dan psikologi telah di usahakan secara maksimal agar tidak mempengaruhi keselamatan dan kesehatan kerja pekerja PT. XYZ Cabang Sumbawa Nusa Tenggara Barat. Jadi, dapat diketahui dari data yang telah diperoleh-disajikan bahwa program K3 sangat berpengaruh positif bagi para pekerja dan penyedia lapangan kerja yaitu PT. XYZ Cabang Sumbawa. Alasannya, jika K3 tidak diterapkan maka banyak kecelakaan dan bahaya yang telah dan akan terjadi sehingga menimbulkan kerugian materi dan jiwa. Akan tetapi, data penelitian menujukkan bahwa K3 berpengaruh positif yang dapat dilihat dari data yang menampilkan tidak adanya kecelakaan para pekerja di PT. XYZ Cabang Sumbawa-NTB.

b. Faktor-faktor yang mempengaruhi iklim kerja

1. Kebisingan

Setelah dilakukan pengukuran, diperoleh bahwa terdapat empat tempat area kebisingan pada PT. XYZ Cabang Sumbawa yang menerobos batas yang telah ditentukan oleh pemerintah yang telah tertuang dalam pedoman teknis penerapan $\mathrm{K} 3$ lingkungan kerja sesuai Permenaker No. 5 Tahun 2018. Keempat tempat tersebut adalah ruang tungku dan dryer yang intensitas kebisingannya $92.0 \mathrm{dBA}^{\mathrm{B}}$, ruang intake jagung 02 yaitu $99.6 \mathrm{dBA}^{\mathrm{B}}$, ruang luaran silo yaitu $89.9 \quad \mathrm{dBA}^{\mathrm{B}}$, dan raung pemuatan jagung 03 yaitu 89.5 $\mathrm{dBA}^{\mathrm{B}}$. Dampak dari keadaan 
tersebut dapat menyebabkan gangguan otak, tuli, stress, cepat marah, dan gangguan tidur.

2. Getaran

Getaran yang dijadikan objek penelitian adalah getaran yang ditimbulkan oleh forklift. Alat uji getaran menggunakan vibration meter.

Berdasarkan hasil uji pengukuran getaran forklift maka diperoleh sebagai berikut

\begin{tabular}{|c|c|c|c|c|}
\hline $\begin{array}{l}\mathrm{N} \\
\mathrm{O}\end{array}$ & Unit & $\begin{array}{l}\text { Kondisi } \\
\text { forklift. }\end{array}$ & $\begin{array}{c}\text { Standar } \\
\text { pemeri } \\
\text { ntah } \\
\left(4 \mathrm{~m} / \mathrm{d}^{2}\right)\end{array}$ & $\begin{array}{c}\text { Getara } \\
\text { n yang } \\
\text { dihasil } \\
\text { kan } \\
\left(\mathrm{m} / \mathrm{s}^{2}\right)\end{array}$ \\
\hline \multirow[b]{2}{*}{1} & \multirow[b]{2}{*}{01} & $\begin{array}{l}\text { Mesin } \\
\text { hidup tapi } \\
\text { tidak jalan }\end{array}$ & $4 \mathrm{~m} / \mathrm{d}^{2}$ & 3.4 \\
\hline & & $\begin{array}{l}\text { Mesin } \\
\text { hidup } \\
\text { sedang } \\
\text { jalan }\end{array}$ & $4 \mathrm{~m} / \mathrm{d}^{2}$ & 5.2 \\
\hline & & & & \\
\hline \multirow[b]{2}{*}{2} & \multirow[b]{2}{*}{02} & $\begin{array}{l}\text { Mesin } \\
\text { hidup tapi } \\
\text { tidak jalan }\end{array}$ & $4 \mathrm{~m} / \mathrm{d}^{2}$ & 3.5 \\
\hline & & $\begin{array}{l}\text { Mesin } \\
\text { hidup } \\
\text { sedang } \\
\text { jalan }\end{array}$ & $4 \mathrm{~m} / \mathrm{d}^{2}$ & 5.5 \\
\hline & & & & \\
\hline \multirow[b]{2}{*}{3} & \multirow[b]{2}{*}{03} & $\begin{array}{l}\text { Mesin } \\
\text { hidup tapi } \\
\text { tidak jalan }\end{array}$ & $4 \mathrm{~m} / \mathrm{d}^{2}$ & 3.5 \\
\hline & & $\begin{array}{l}\text { Mesin } \\
\text { hidup } \\
\text { sedang } \\
\text { jalan }\end{array}$ & $4 \mathrm{~m} / \mathrm{d}^{2}$ & 5.6 \\
\hline
\end{tabular}

Dari data hasil uji getaran yang terlihat, maka dapat diketahui bahwa getaran yang dihasilkan oleh alat kerja yang ada pada PT. XYZ cabang Sumbawa melebihi ambang batas sesuai Permenaker No.5 tahun 2018. Walaupun demikian, kegiatan produksi tetap berjalan lancar dan para pekerja bekerja menerapakan kehatikehatian. Namun, kondisi tersebut menjadi masalah bagi PT. XYZ cabang Sumbawa apabila tidak segera diselesaikan

3. Suhu dan Kelembaban

Dari data yang telah ditemukan bahwa suhu dan kelembaban pada gudang gabah yaitu $31^{\circ} \mathrm{C}$ tertinggi dan terrendah $28^{\circ} \mathrm{C}$. Keadaan suhu tersebut melebihi batas maksimal standar pemerintah atau permenaker No. 5 Tahun 2018 yaitu $28^{\circ} \mathrm{c}$. Semetara kelembaban masih dibawah batas minimal yang dizinkan oleh oleh pemerintah yaitu $65 \%$. Jadi, pada gudang gabah di PT. XYZ Cabang Sumbawa pada keadaan suhu menerobos permenaker No. 5 Tahun 2018 sedangkan pada posisi kelembaban hampir menerobos yaitu $62 \%$ dari yang telah ditetapkan yaitu $65 \%$.

Sementara, pada suhu maupun kelembaban pada gudang jagung tidak melebih batas maksimal yang telah ditentukan oleh pemerintah melalui permenaker No. 5 tahun 2018 yaitu suhu untuk didalam dan diluar ruangan batas maksimalnya $28^{\circ} \mathrm{c}$. Kemudian, pada posisi kelembaban rata-rata dibawah batas minimal yaitu $45 \%$ dari permenaker No. 5 tahun 2018 yaitu $65 \%$.

\section{Kecepatan angin}

keberadaan atau keadaan kecepatan angin di PT. XYZ Sumbawa Nusa Tenggara Barat masih normal baik pada tempat pengolahan jagung maupun gabah yaitu maksimumnya 20-21 mph dan minimunya $10 \mathrm{mph}$. keadaan tersebut masih lebih rendah dari batas yang telah ditentukan oleh pemerintah yaitu $40 \mathrm{mph}$. Jadi, di PT. XYZ Sumbawa Nusa Tenggara Barat memperhatikan-menerapkan keselamatan dan kesehatan kerja sesuai dengan Permenaker No.5 Tahun 2015 yang menekankan bahwa setiap perusahaan harus memperhatikan batas maksimal keadaan kecepatan angin yaitu 40 mph. 
5. Air

Pengujian air dilakukan untuk menjamin kesehatan para pekerja PT. XYZ cabang Sumbawa.

Dari hasil temuan dilapangan bahwa air di PT. XYZ cabang Sumbawa masih di normal yaitu warnanya jernih, PHnya 6.68, suhunya $32.9^{\circ} \mathrm{c}-33.2{ }^{\circ} \mathrm{c}, \quad$ dan TDSnya minimal 0.532

Maksimulm 0.541

6. Pencahayaan

Iklim kerja berupa cahaya atau pencahayaan di PT. XYZ cabang Sumbawa masih jauh dari batas yang telah ditentukan oleh pemerintah yaitu 17 lux-93 lux. Ini artinya bahwa PT. XYZ cabang Sumbawa memperhatikanmengatur iklim cahaya agar tidak bertentangan permenaker No. 5 Tahun 2018. Jadi, faktor pencayaan di PT. XYZ cabang Sumbawa pada ruang pengolahan jagung dan gabah menerapakan keselamatan dan kesehatan kerja sesuai dengan permenaker No. 5 Tahun 2018 agar stabilitas dan produktivitas PT. $\mathrm{XYZ}$ cabang Sumbawa tetap terjaga dan utuh keberadaannya.

\section{PEMBAHASAN}

Iklim Kerja

Iklim kerja adalah suatu kombinasi dari keadaan tempat kerja seperti getaran, kebisingan, cahaya, dan angin. Iklim kerja yang tidak nyaman, tidak sesuai dengan syarat yang ditentukan dapat menurunkan kapasitas kerja yang berakibat menurunnya efisiensi dan produktifitas kerja. Iklim kerja yang tidak nyaman dan aman akan menimbulkan berbagai masalah bagi para pekerja itu seperti gatal-gatal, dehidrasi, kelelahan, dan kekakuan otot. Jadi, iklim kerja merupakan salah satu faktor fisik yang berpotensi menimbulkan potensi bahaya yang dapat menimbulkan gangguan kesehatan terhadap tenaga kerja bila berada pada kondisi yang ekstrim panas dan dingin dengan kadar yang melebihi nilai ambang batas ketahanan tubuh pekerja. Terkait dengan PT. XYZ Cabang Sumbawa, terdapat iklim kerja yang sesuai dengan permenaker No. Tahun 2018 dan sebaliknya. Pada tempat pengolahan jagung dan gabah, PT. XYZ Cabang Sumbawa menyimpan iklim kerja yang memuat getaran, kebisingan, pencahayaan ruang kerja, suhu dan kelembaban, kecepatan angin, dan air. Akan tetapi, getaran, kebisingan, dan suhu dan kelembaban menawarkan bahaya bagi pekerja karena tidak sesuai dengan permenaker No. 5 Tahun 2018. Apapun itu, Kesehatan dan Keselamatan Kerja (K3) harus diterapakan karena merupakan aspek perlindungan tenaga kerja sekaligus melindungi aset perusahaan. Tujuannya, memberikan jaminan kondisi yang aman dan sehat kepada setiap karyawan dan untuk melindungi sumber daya manusia dan untuk mengurangi angka kecelakaan kerja khususnya. Untuk itu, agar tercipta lingkungan kerja yang sesuai dengan permenaker No. 5 Tahun 2018; baik perusahaan maupun pekerja perlu melakukan pembinaan dan pelatihan, pengarahan, dan control terhadap pelaksanaan tugas dari para karyawan dan pemberiaan bantuan sesuai dengan aturan yang berlaku, baik dari lembaga pemerintah maupun perusahaan yang memiliki pekerja.

Pemerintah memberikan perhatin khusus berupa penetapan aturan melalui Permenaker No 5 Tahun 2018. Aturan ini tidak dibuat untuk dijadikan bahan bacaan semata, namun untuk menjadi setiap pelaku kerja agar sebagai berikut:

1. Terjadinya peningkatan pengetahuan tentang kerja

2. Terciptanya lingkungan kerja yang sehat, nyaman, dan aman.

3. Penggunaan alat-alat kerja dapat disesuaikan untuk menjamin keselamatan kerja

4. Kecelakaan dapat dicegah sehingga tidak menimbulkan korban kesehatan atau jiwa 
5. Menekan kerugian akibat biaya operasional perusahaan seperti layanan santunan kecelakaan atau korban jiwa.

6. Terjadinya peningkatan pendapatan atau produktivitas yang efektif dan efisien.

7. Tercegahnya faktor-faktor yang menimbulkan kerugian seperti faktor kimia, biologi, fisika, dan fisiologi.

\section{Dampak K3 sesuai Permenaker No 5 Tahun 2018}

Dalam bekerja, Keselamatan dan Kesehatan Kerja (K3) merupakan faktor yang sangat penting untuk diperhatikan karena seseorang yang mengalami sakit dalam bekerja akan berdampak pada diri, keluarga, lingkungannya, dan tempat kerjanya. Untuk itu, pemerintah memberikan perhatin khusus berupa penetapan aturan melalui Permenaker No 5 Tahun 2018. Aturan ini tidak dibuat untuk dijadikan bahan bacaan semata, namun untuk menjadi setiap pelaku kerja agar sebagai berikut:

a Terjadinya peningkatan pengetahuan tentang kerja

b Terciptanya lingkungan kerja yang sehat, nyaman, dan aman.

c Penggunaan alat-alat kerja dapat disesuaikan untuk menjamin keselamatan kerja

d Kecelakaan dapat dicegah sehingga tidak menimbulkan korban kesehatan atau jiwa

e Menekan kerugian akibat biaya operasional perusahaan seperti layanan santunan kecelakaan atau korban jiwa.

f Terjadinya peningkatan pendapatan atau produktivitas yang efektif dan efisien.

g Tercegahnya faktor-faktor yang menimbulkan kerugian seperti faktor kimia, biologi, fisika, dan fisiologi.

\section{Kebijakan PT. XYZ Cabang Sumbawa tentang $\mathrm{K} 3$ terhadap Pekerjanya.}

PT. XYZ Cabang Sumbawa merupakan perusahaan yang berorientasi pada pengolahan jagung dan gabah. Kegiatan pengolahan jagung dan gabah sebagian besar menggunakan mesin dan alat berat.

Untuk menghindari terjadinya dampak buruk pekerjaan, maka PT. XYZ Cabang Sumbawa menerapkan hal-hal sebagi berikut:

1. Menanamkan sikap dan rasa memiliki pekerjaan dan perusahaan agar perusahaan dapat berkembang dan maju.

2. Setiap pekerja harus dapat memimpin, mengatur, dan mengoreksi satu sama lain.

3. K3 bukan tanggung jawab perusahaan semata tapi juga pekerja. Jadi perlu partisipasi semua pihak di perusahaan agar pekerjaan tetap sehat, selamat, dan nyaman.

Untuk antisipasi terjadinya kecelakaan ditempat kerja, PT. XYZ Cabang Sumbawa menerapkan hal-hal sebagi berikut:

1. Pengendalian teknik: yaitu mengganti prosedur kerja, menutup mengisolasi bahan berbahaya, menggunakan otomatisasi pekerjaan, menggunakan cara kerja basah dan ventilasi udara.

2. Pengendalian administrasi yaitu mengurangi waktu pajanan, menyusun peraturan keselamatan dan kesehatan, memakai alat pelindung diri, memasang tanda-tanda peringatan, membuat daftar data bahan-bahan yang aman, melakukan pelatihan sistem penangganan darurat.

3. Pemantauan kesehatan : melakukan pemeriksaan kesehatan seluruh pekerja secara berkala

\section{H. KESIMPULAN DAN SARAN}

\section{KESIMPULAN}

Berdasarkan hasil kajian teori dan data yang bersumber dari penelitian yang telah dilakukan di tempat pengelolahan jagung gabah yaitu di PT. XYZ Cabang Sumbawa tentang iklim kerja lingkungan K3 bahwa keselamatan dan kesehatan kerja merupakan suatu usaha dan upaya untuk menciptakan perlindungan dan keamanan dari risiko kecelakaan dan bahaya baik fisik, mental maupun emosional terhadap 
pekerja, perusahaan, dan masyarakat. Dari data yang telah ditemukan bahwa semua pekerja PT. XYZ Cabang Sumbawa tidak mengalami kecelakaan kerja atau semua aktivitas kerja PT. XYZ Cabang Sumbawa berjalan lancar saja tanpa ada keluhan dari pekerjanya sendiri. Ini menujukkan bahwa program K3 berpengaruh baik pada pekerja PT. XYZ Cabang Sumbawa.

Untuk faktor-faktor yang mempengaruhi iklim kerja seperti kebisingan, getaran, suhu dan kelembapan, kecepatan angin, air dan pencahayaan yang dimaksud dalam Permenaker No.5 tahun 2018 tidak berpengaruh dalam kegiatan kerja para karyawan dan pekerja di PT. XYZ Sumbawa Nusa Tenggara Barat. Sementara, iklim kerja K3 sesuai Permenaker No.5 tahun 2018 tidak semuanya diterapkan oleh PT. XYZ Cabang Sumbawa. Kondisi ini muncul karena terdapat beberapa ilim kerja yang tidak sesuai dengan standar pemerintah yaitu kebisingan, getaran, dan suhu dan kelembaban ruang kerja. Sementara itu, pencahayaan, kecepatan angin, dan air sesuai dengan permenaker No. 5 tahun 2018. Keadaan tersebut akan berdampak buruk bagi kelangsungan kesehatan dan keselamatan pekerja dan PT. XYZ Cabang Sumbawa Walaupu demikian, semua pekerja pada tempat pengolahan jagung dan gabah di PT. XYZ Cabang Sumbawa tidak mengalami gangguan atau kecelakaan kerja.

\section{SARAN}

a. PT. XYZ Cabang Sumbawa agar selalu mengutamatakan kesehatan dan keselamtan kerja agar segala bentuk kecelakaan dan akibatnya dapat dihindari.

b. PT. XYZ Cabang Sumbawa selama pengelolahan jagung dan gabah hendak melakukan upaya keselamatan dan kesehatan kerja untuk menciptakan suasana kerja yang aman dari risiko kecelakaan kecelakaan baik fisik, mental maupun emosional sehingga memberikan perlindungan kepada tenaga kerja.

c. Keselamatan dan kesehatan kerja merupakan program bersama menyelamatkan jiwa, maka dibutuhkan peran serta setiap unit kerja PT. XYZ Cabang Sumbawa.

d. Untuk meningkatkan hasil kerja dan produktivitas kerja, para tenaga kerja PT. XYZ Cabang Sumbawa harus memperoleh jaminan perlindungan keselamatan dan kesehatannya di dalam setiap pelaksanaan pekerjaannya seharihari.

e. Setiap pekerja PT. XYZ Cabang Sumbawa harus senantiasa memakai alat pelindung diri untuk mencegah keburukan yang tidak diketahui terjadinya.

\section{DAFTAR PUSTAKA}

Ahmadi, 2009. Psikologi Sosial. Rineka Cipta: Jakarta.

A.M. Sugeng Budiono, 2003, Bunga Rampai Hiperkes, Semarang : Universitas Diponegoro.

Ardyanto, 2005. Potret Iklim Kerja, Jurnal kesehatan lingkungan, Volume 1, No 2, hlm 142-151.

Harrington dan Gill, 2005.Buku Saku Kesehatan Kerja. Jakarta: EGC.

John Ridley, 2008. Kesehatan dan Keselamatan Kerja.Erlangga. Jakarta.

Peraturan Menteri Ketenagakerjaan Republik Indonesia Nomor 5 Tahun 2018 tentang Keselamatan dan Kesehatan Kerja Lingkungan Kerja.

Gita Fajrianti, Zahroh Shaluhiyah, Daru Lestantyo, 2017. Pengendalian Heat Stress Pada Tenaga Kerja di Bagian Furnace PT. X Pangkalpinang Bangka Belitung. Jurnal Promosi Kesehatan Indonesia Vol. 12 / No. 2.

Suma'mur, 2009. Higiene Perusahaan dan Kesehatan Kerja (HIPERKES). Jakarta: Sagung Seto. 